reversal was effected through nutrition, it could have been a response to the accumulation of some specific substance. On the other hand, it is probably due ultimately to a change in endocrine activity ${ }^{4}$, and this might well have been brought about independently of nutrition.

Aphids of many species are attended by ants, and the influence of ants in causing the suppression of alatiform structures in developing nymphs is undoubtedly of widespread occurrence. But alate aphids are sometimes produced in large numbers, particularly on wilting or dying host plants. On such plants, the aphids' rate of feeding, and thus excretion, are reduced. As a result, fewer ants tend the aphids; individual aphids are visited less often, and there must come a stage when the effects of infrequent ant-attendance are outweighed by the alate-favouring factors of the aphids' environment, and the aphids then develop into alatae.

\section{Bruce Johnson}

Waite Agricultural Research Institute, University of Adelaide. May 12.

1 El-Ziady, S., and Kennedy, J. S., Proc. Roy. Ent. Soc., A, 31, 61 (1956) Banks, J. C., Bull. Ent. Res 49, 701 (1958).

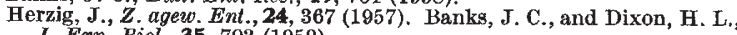
J. Exp. Biol., 35, 703 (1959)

Wadley, B., Ent. Exp. and Appl. (in the press)

P. R. (in Iit.).

\section{MICROBIOLOGY}

\section{Transaminases in Shigellæ}

Numrrous investigations have been made of the transaminase system in bacteria, and these have been reviewed by Meister ${ }^{1}$. The only reference to the transaminase activity in Shigelloe appears to be the one mentioned by Lichstein and Cohen ${ }^{2}$ on a strain of Shigella dysenteriae (Shiga).

Using acetone-dried cell preparations, the transaminase activity of nine strains of Shigelloe was studied. The strains were chosen from the four serological groups, and were Shigella dysenteriae 6, Shigella dysenteriae 7, Shigella boydii 2, Shigella boydii 3, Shigella boydii 5 , Shigella flexneri $1 a$, Shigella flexneri $2 a$, and two strains of Shigella sonnei. The strains were grown on nutrient broth ${ }^{3}$ at $37^{\circ} \mathrm{C}$. for $18 \mathrm{hr}$, and seeded on to the surface of 1.8 per cent nutrient agar (New Zealand agar) in Roux bottles. Following overnight aerobic incubation at $37^{\circ} \mathrm{C}$., the growth was washed off with ice-cold sterile double-distilled water and an acetone-dried cell preparation obtained by the method of Umbreit et al.4

Four keto-acids, $\alpha$-ketoglutarate, oxalo-acetic acid, sodium pyruvate and sodium phenyl pyruvate were used in concentrations of $0 \cdot 25 M$ at $p H \quad 8 \cdot 2$. The amino-acids serving as $\mathrm{NH}_{2}$-group donor were $l$-arginine, $d l$-methionine, $d l$-histidine, glycine, $d l$ serine, $d l$-tryptophan, $d l$-valine, $d l$-aspartic acid, $d l$-phenyl alanine, $d l$-alanine and $d l$-glutamic acid. $d l$-Tryptophan, $l$-arginine and glycine were prepared in concentrations of $0.1 \mathrm{M}$; all other amino-acids were in concentrations of $0.2 M$. The experiments followed, in general, the methods described by Gunsalus and Stamer ${ }^{5}$. The reactants were $0.1 \mathrm{ml}$. $M$-phosphate buffer $(p H \mathrm{H} \cdot 3), 0.2 \mathrm{ml}$. of a homogeneous aqueous suspension of acetone-dried cells ( $30 \mathrm{mgm} . / \mathrm{ml}$ ), $0 \cdot 2 \mathrm{ml}$. pyridoxal phosphate $(0.5 \mathrm{mgm} . / 10 \mathrm{ml}$.), $0 \cdot 2 \mathrm{ml}$. aminoacid, $0.1 \mathrm{ml}$. keto-acid and water to make up to $1.0 \mathrm{ml}$.
The reaction of the mixture was adjusted to $p \mathrm{H} \mathrm{8.2}$. The cell suspension boiled at $100^{\circ} \mathrm{C}$. for $3 \mathrm{~min}$. was used as control for each amino-acid - keto-acid experiment. The tubes were incubated for $60 \mathrm{~min}$. at $37^{\circ} \mathrm{C}$., and the reaction stopped by boiling at $100^{\circ} \mathrm{C}$. for 5 min. ${ }^{6}$ The tubes were centrifuged at 3,000 r.p.m. for $30 \mathrm{~min}$., and approximately $0.002 \mathrm{ml}$. of the supernatant examined for the presence of the amino-acid corresponding to the keto-acid used, by qualitative paper chromatography.

With all the strains used, the following reversible reactions were shown to occur:

(a) glutamic acid + oxaloacetic acid $\rightleftharpoons$ aspartic acid + ketoglutarate;

(b) glutamic acid + sodium pyruvate $\rightleftharpoons$ alanine + ketoglutarate;

(c) glutamic acid + sodium phenyl pyruvate $\rightleftharpoons$ phenyl alanine + ketoglutarate.

In addition, aspartic acid was formed in the reaction between phenyl alanine and oxaloacetic acid with cell preparations of the strains of Shigella dysenteriae 6, Shigella boydii 3, Shigella boydii 5 , and one strain of Shigella sonnei. Alanine was present in the supernatant of the reaction mixture containing aspartic acid and sodium pyruvate with the strains of Shigella dysenteriae 3, Shigella boydii 3 and Shigella boydii 5 . With the strains of Shigella boydii 5 and Shigella dysenteriae 6, alanine was also formed in the reaction between phenyl alanine and sodium pyruvate.

Of the four keto-acids, $\alpha$-ketoglutarate was most active, and showed reactions with methionine, valine, tryptophan, phenyl alanine, alanine and aspartic acid. Phenyl pyruvate showed the lowest activity. Of the two remaining keto-acids, both of which were poorer amino acceptors than ketoglutarate, oxaloacetic acid was slightly more active than sodium pyruvate. Among the amino donors, glutamic acid showed reaction with the three keto acids, and the reaction could be demonstrated with all the strains used. Under conditions of the test, none of the strains was able to show transamination reactions with glycine, serine, histidine and arginine, and any one of the four ketoacids.

I am grateful to Prof. P. Collard, Department of Bacteriology, University College, Ibadan, for his helpful advice and criticism, and to Dr. J. H. Marshall of the Department of Bacteriology, London School of Hygiene and Tropical Medicine, for helpful discussions.

Department of Bacteriology,

RANJIT SEN

University College, Ibadan,

Nigeria, West Africa.

May 11.

1 Meister, A., "Adv. in Enzymol.", 16, 185 (1955).

${ }^{2}$ Lichstein, H. C., and Cohen, P. P., J. Biol. Chem., 157, 85 (1945).

Mackie, T. J., and Mccartney, J., E., "Handbook of Practical Bacteriology", 8th ed. (E. and S. Livingstone Xtd., Edinburgh, 1950).

mbreit, W. W., Burris, E, H., and Stauffer, J. H., "Manometric Techniques and Tissue Metabolism"' (Burgess Publishing Co., Minneapolis 1951).

ed. S, I. C., and Stamer, J. R., "Methods of Enzymology", Vol. 2. ed. S. P. Colowick and N. O. Kaplan (Academic Press Inc., New - Rudman, D., and Meister, A., J, Biol. Chem, 200, 591 (1953).

\section{Light-Induced Production of Carotenoid Pigments by Cephalosporia}

THE pink and orange pigmentation in cultures of various members of the form genus Cephalosporium has been noted by several authors ${ }^{1}$. Roberts ${ }^{2}$ presents a table including descriptions of the colony colour of $\mathbf{a}$ number of Cephalosporium species and strains without 